\title{
The Awareness Level of Hunters Related To Making Environmental Mistakes in the Dukan Lake - Sulaimaniyah Governorate
}

\author{
Dara.A.Salih Kalhory \\ Department of ARD / Collage of Agricultural Engineering Sciences /University of Sulaimani \\ dara.abdulrahman@univsul.edu.iq
}

\begin{abstract}
The study aims to identify the awareness level of Hunters related to making environmental mistakes in the Dukan lake - Sulaimaniyah Governorate. The study comminuted included all 177 respondents in the study area and the study sample included 62 respondents who randomly selected $35 \%$ of the study comminuted as well as the questionnaire by interview was used as a tool to collect the data then the questionnaire was shown to specialists in agricultural extension and fish breeders to achieve content validity. The data was collected and analyzed statistically by used statistical tools and SPSS version22. As well as the results showed that $\% 82.25$ of respondents were aware related to making environmental mistakes in general within medium tends to low. Also, the awareness level of respondents related to fields of making mistakes that caused water pollution came the first rank in terms of relative importance with means of 30.11 degrees. Then comes Soil pollution with means of 19.88 degrees. Finally, Air pollution comes in the last rank with means of 19.45 degrees. Additionally, the results show that there is a correlation between the awareness level of respondents related to making environmental mistakes in the Dukan lake - Sulaimaniyah Governorate in general and variables: Age and Duration of fishing experience While there is no correlation between the awareness level of respondents related to making environmental mistakes in general and each of variables: Areas Used in fishing, Participation in training courses and Exposure to informational sources.
\end{abstract}

Keyword: Awareness level of Hunters, Environment, Making Mistakes.

\section{Introduction}

Human beings are the most important factor in bringing related to environmental change and biological natural degradation because it deals directly with environmental components and a problem in the environment occurs as a result of the negative effects of human productivity

\section{Dates:}

Received: 05 March 2021

Accepted 11 April 2021

Published: 30 June 2021 
activities on the size of natural resources. So, Environmental pollution of all kinds is one of the biggest problems facing societies. (Alloush, 2016).

These negative effects on the environment in Iraq are detected in the lack and pollution of the water resources, air pollution and the deterioration of air quality, a reduction in biodiversity, and the pollution of marine waters (World Bank, 2017). As well as Iraq faces serious environmental problems, water poorness, soil salinity, air pollution, and conflict pollution to the deterioration of key ecosystems, climate change impacts, and the threat of water shortages. (K4D).

As point out each of Al-Najjar, 1992; Abdul Salam and Arafat, 1992; Arnaout,1993; AlSaffty,2008; Nathanson, 2000 and Holum,1997 "The environmental pollution in this century its degree has exceeded the safety limits and reached humanity to the dangerous stage, which poses a great danger to the living and non-living in all its forms and images".

Although, there are rules for assessing the impact of the environment in Iraq yet they are not effective as well as development projects need to address environmental impacts for them to succeed. (Nature Iraq, 2004)

In addition, Tahir (2020) indicates that the Dukan lake in Sulaimaniyah Governorate during the years 2018-2020 has been subjected to a loss of biological balance as a result of the discharges of increasing organic loads of agricultural and industrial wastewater, daily human activities, lack of annual rain, in addition to its impact on soil pollution in particular. As well as The previous challenges had a profound impact there has been a noticeable decline in the fish wealth, as well as a deterioration in the quality of the water due to the wastewater and the poor living and economic conditions of the fishermen, and they became a source of concern for the government agencies. (AS. P, D. WR, 2010)

As well as lack of awareness within the public and the absence of effective educational and awareness campaigns to build the knowledge base of the public for responsible water usage. (N.I.P, 2001). As well as all the reasons mentioned make the fishermen reconsider their wrong fishing practices and change their behavioral patterns in a way that suits their profession and work in the Kurdistan Region. (Muhamad, 2019)

Hence, there is a role of agricultural extension in achieving social and economic development and that is through changing the behavioral patterns of the agents to match with the problems and requirements of local conditions. (Abdul Ghaffar, 1975 and Al-Adly, 1973).

Also, the role of agricultural extension in making desired and specific behavioral changes in the behavior of the individual as well as the desired behavioral changes begin with changes in the individual's knowledge, experiences, inclinations, and beliefs and a change in his skills until we reach the desired change. (Zahran, A. and Qasim, 2005) On this basis, the current study was chosen.

Therefore, the current study will be based on the following questions to identifying the awareness level of Hunters related to making environmental mistakes in the study area. 
1. What is the awareness level of Hunters related to making environmental mistakes in the Dukan lake in general?

2. What is the awareness level of Hunters related to fields of making mistakes that pollute the Dukan lake environment?

3. How are the fields of making mistakes that pollute the environment are arranged according to the degree of importance?

4. What is the relationship between the awareness level of hunter related to making environmental mistakes in general and personal and communicative variables?

\section{Study Objectives:}

1. Identifying the awareness level of Hunters related to making environmental mistakes in the Dukan lake in general.

2. Identifying the awareness level of Hunters related to fields of making mistakes that pollute the Dukan lake environment.

3. Arranged the fields of making mistakes that pollute the Dukan lake environment according to the degree of importance.

4. Identifying the relationship between the awareness level of hunter related to making environmental mistakes in general and personal and communicative variables

\section{Materials and methods}

\section{Study Methodology:}

Use the descriptive method in the current study witch it aims to Identify the awareness level of Hunters related to making environmental mistakes in the Dukan lake in Sulaimaniyah Governorate.

\section{Study Region:}

The current study included the areas of Khadran and Boskin Village on The Dukan Lake in Sulaimaniyah Governorate, this area was chosen based on the statistics and data issued by the Planning and follow-up department (M.A.W.R, 2020 ) in the General Directorate of Agriculture and Irrigation in Sulaimaniyah Governorate.

\section{Study Community and Sample:}

The Study comminuted includes 177 respondents in the study area, and the study sample included 62 respondents who randomly selected $35 \%$ of the study community.

\section{Preparation of Study tools:}

The current study uses the questionnaire tool to collect data, and the form has been prepared in two parts: 
The first part was designed to study are personal and communicative characteristics of the respondents, which include the following variables: Age, Duration of fishing experience Areas Used in fishing, Participation in training courses, and Exposure to informational sources.

The second part relates to the main objectives of this study, which is to Identify the awareness level of Hunters related to making environmental mistakes in the Dukan lake in Sulaimaniyah Governorate.

In light of the study objectives, the questions have been formulated, which include Hunters' awareness level of relates the fields of mistakes that cause pollution of Water, Soil, and Air respectively according to relative importance, and consists of 20 items and distributed as follows: Water pollution 8 Soil pollution 6 Items and Air pollution 6 Items. Then to measure items related to the study objectives, the Likert scale was used following very high, high, neutral, low, and Non-influence) and grades were set $(5,4,3,2,1)$ respectively. Before starting data collection, the pre-test was used to ensure the final validity and reliability of the questionnaire.

To achieve the validity was reviewed by experts, Experts, and specialists in the fields of Agricultural extension, Natural resources, and Fisheries to take their opinions and decide on the content and formulate of Items and fields of the form with giving the relative weights to be prepared in primitive form. As well depending on their views, the items were reformulated, Reliability was measured through the exploratory sample of 17 respondents in the Sirwan district, as well as to identify the reliability using Cronbach's Alpha coefficient. (AL. Abbassi, 2018). So, the reliability coefficient was 0.74 degree. It has appeared that the scale had a mean value above 0.70 which is indicating to acceptable reliability.

Finally, the data was collected during the period (13-15, Nov. 2020), the data were arranged and classified after analyzing with SPSS version22 software. The statistical tools used to analyze the data are Number, percentage, Means, standard deviation, Cronbach's Alpha. T-test.

\section{Results and Discussion}

First: Determining the awareness level of Hunters related to making environmental mistakes during fishing in the Dukan lake in general.

To Identify the level of awareness of Hunters related to making environmental mistakes during fishing in general, the respondents were classified into three levels depending on the actual range described in Table 1:

Table 1. The awareness level of respondents in general

\begin{tabular}{|c|c|c|c|}
\hline Categories & $\mathrm{N}$ & $\%$ & Mean \\
\hline$(54-65)$ & 21 & 33.87 & 60.52 \\
\hline Medium (66-77) & 30 & 48.38 & 71.23 \\
\hline$(78-89)$ & 11 & 17.75 & 81.63 \\
\hline Total & 62 & 100 & \\
\hline
\end{tabular}


As a result, Table 1 shows that $82.25 \%$ of respondents indicated that the general level of awareness of environmental mistakes made tended from medium to low. Refers to Lack of environmental awareness in general or the lack of awareness of fishermen and those who are work with them on the extension recommendations for protecting the water environment in the study area.

Second: Identifying the awareness level of Hunters related to the fields of making mistakes that pollute the Dukan lake environment.

Respondents were distributed according to their performance of environmental mistakes made during fishing in three fields: water, soil, and air pollution, as shown in table 2:

Table 2. Fields of making environmental mistakes by respondents and their rank

\begin{tabular}{|c|c|c|c|c|c|c|c|}
\hline $\begin{array}{c}\text { Fields of } \\
\text { environmental } \\
\text { mistakes }\end{array}$ & Mean & S.D & Mini & Maxi & $\begin{array}{c}\text { Standerd } \\
\text { Mean }\end{array}$ & $\begin{array}{c}\text { Relative } \\
\text { Importance }\end{array}$ & Rank \\
\hline Water pollution & 30.11 & 6.10 & 21 & 38 & 40 & 75.22 & 1 \\
\hline Soil Pollution & 19.88 & 4.68 & 11 & 28 & 30 & 66.45 & 2 \\
\hline Air Pollution & 19.45 & 4.85 & 12 & 29 & 30 & 63.13 & 3 \\
\hline
\end{tabular}

As a result, table 2 Show that the awareness level of Hunters that the making mistakes that caused water pollution in the first rank in terms of relative importance, with the maximum Numeric value received by respondents at 38 degrees and the minimum value being 21 degrees and 30.11 degrees. The result is referred to that the respondents have sufficient information about the results of practicing errors related to their profession that result in pollution in the water environment. As well as come to the mistakes that cause air pollution, with an average of 19.88 degrees. The reason may be due to the low level of awareness of the respondents related to the non-fishing activities such as digging irrigation canals to raise fish in cages or establishing a shelter for livestock near the lake. Then comes the mistakes that cause air pollution, with an average of 19.88 degrees. The reason may be that the respondents rely on traditional information sources and they use them during their fishing activities that produce air pollution in their work area.

Third: Arranged the fields of making mistakes that pollute the Dukan lake environment according to the degree of importance.

The search results showed the mean to the important degree which the respondents gave to each of items in the Water, Soil and Air pollution which includes: Table 3. 
Table 3. Items of making environmental mistakes that pollute of the Dukan lake and its arranged

\begin{tabular}{|c|c|c|c|c|}
\hline $\begin{array}{c}\text { Fields of } \\
\text { environmental } \\
\text { mistakes }\end{array}$ & Items & Mean & $\%$ & Rank \\
\hline \multirow{8}{*}{ 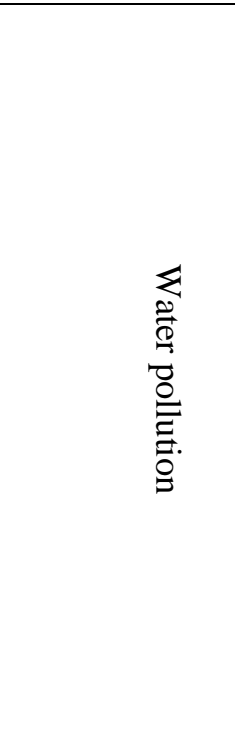 } & $\begin{array}{l}\text { Waste from agricultural wastewater: } \\
\text { Pesticides and Chemical fertilizers }\end{array}$ & 4.43 & 11.07 & 1 \\
\hline & $\begin{array}{l}\text { Dumping waste and waste tourism (Non- } \\
\text { hunting) to the edge of the beach }\end{array}$ & 4.03 & 10.07 & 2 \\
\hline & $\begin{array}{l}\text { Heavy metals in the lake which produced } \\
\text { from industrial wastewater. }\end{array}$ & 4.01 & 10.02 & 3 \\
\hline & $\begin{array}{l}\text { Waste from the maintenance and operation of } \\
\text { boats. }\end{array}$ & 4 & 10 & 4 \\
\hline & Use of toxic substances for fishing. & 3.95 & 9.87 & 5 \\
\hline & $\begin{array}{l}\text { Washing dishes and clothes with chemical } \\
\text { cleaners (Soap) by fishermen }\end{array}$ & 3.61 & 9.02 & 6 \\
\hline & $\begin{array}{l}\text { Throwing dead animals and birds with lake } \\
\text { water. }\end{array}$ & 3.19 & 7.97 & 7 \\
\hline & $\begin{array}{l}\text { Waste from washing fishing gear and boats } \\
\text { after use. }\end{array}$ & 2.91 & 7.27 & 8 \\
\hline \multirow{6}{*}{ 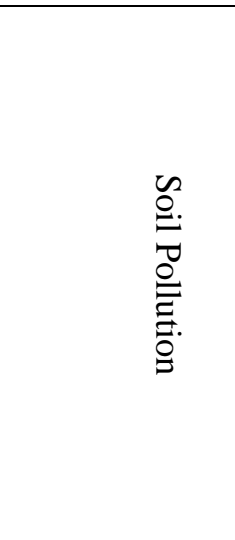 } & Clearing the lake floor with excavators & 3.91 & 13.03 & 1 \\
\hline & $\begin{array}{l}\text { Disinfection of soil and water by opening } \\
\text { Canal or corridors within the lake. }\end{array}$ & 3.64 & 12.12 & 2 \\
\hline & $\begin{array}{l}\text { Making small dams for the internal expenses } \\
\text { of the lake to raise fish in cages. }\end{array}$ & 3.41 & 11.36 & 3 \\
\hline & $\begin{array}{l}\text { Filling part of the lake-shore to make barns } \\
\text { and housing for livestock. }\end{array}$ & 3.35 & 11.16 & 4 \\
\hline & $\begin{array}{l}\text { Throwing construction waste and roads } \\
\text { housing to the edge of the beach. }\end{array}$ & 3.30 & 11 & 5 \\
\hline & $\begin{array}{l}\text { Boat debris and damaged fishing nets on the } \\
\text { Edge of the beach. }\end{array}$ & 2.24 & 7.46 & 6 \\
\hline \multirow{6}{*}{ 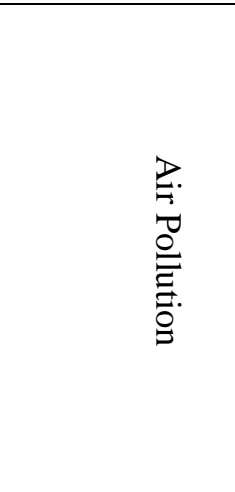 } & Burning grass on the edge of the lake & 3.62 & 12.06 & 1 \\
\hline & $\begin{array}{l}\text { Dumping solid garbage and human waste } \\
\text { used while fishing inside the lake and its edge }\end{array}$ & 3.32 & 11.06 & 2 \\
\hline & $\begin{array}{l}\text { Throwing livestock waste on the edge of the } \\
\text { lake. }\end{array}$ & 3.30 & 11 & 3 \\
\hline & $\begin{array}{l}\text { Throwing dead fish and fishing waste into the } \\
\text { lake water. }\end{array}$ & 3.25 & 10.83 & 4 \\
\hline & Use of poultry bowel residues during fishing. & 3.19 & 10.63 & 5 \\
\hline & $\begin{array}{l}\text { The presence of a contaminated water pond } \\
\text { on the edge of lake canals }\end{array}$ & 2.74 & 9.13 & 6 \\
\hline
\end{tabular}


As a result, Table 3 Show that the Items making mistakes that causing Water pollution came in the first rank in terms of relative importance, and the Item of (Waste from agricultural wastewater: Pesticides and Chemical fertilizers) came at the first rank and with an average 4.43 degree is due to the water area is not intended for fishermen only, but rather the area is used for tourism or agriculture, which negatively affects the water environment of the lake. Then the Items of making mistakes that causing Soil pollution second rank in terms of importance, and the Item of (Clearing the lake floor with excavators) came at the first rank and with an average of 3.91 degree is due to the use of machinery to dig the lake floor and make a livestock dwelling by fishermen and livestock breeders negatively affect the working environment of fishermen and the environment of Dukan Lake in particular.

Finally, the Items of making mistakes that causing Air pollution third rank in terms of importance and the Item of (Burning grass on the edge of the lake) came at the first rank and with an average 3.62 degree is due to fishermen burn weeds and livestock creations to prepare food and shelter for them at night, which causes air and water pollution and lake water at the same time.

Fourth: Determining the relationship between the awareness level of hunter related to making environmental mistakes in general and personal and communicative variables.

Table 4. Socioeconomic data of responses in Sulaimaniyah governorate

\begin{tabular}{|c|c|c|c|c|c|}
\hline Variables & Categories & $\mathrm{N}$ & $\%$ & Means & Notes \\
\hline & $20-29$ & 23 & 37.09 & 68.47 & Correlation $=0.232$ \\
\hline \multirow[t]{2}{*}{ Age/ years } & $30-39$ & 24 & 38.71 & 68.57 & Sign $^{(0.005)}$ \\
\hline & $40-49$ & 15 & 24.20 & 72.33 & $\mathrm{X}^{-}=33.22, \mathrm{~S} . \mathrm{d}=6.74$ \\
\hline Duration of & $2-7$ & 25 & 40.30 & 67.32 & Correlation $=0.988$ \\
\hline experience in & $8-13$ & 24 & 38.70 & 69.54 & $\operatorname{Sign}^{(0.001)}$ \\
\hline fishing/years & 14-19 & 13 & 21 & 73.38 & $\mathrm{X}^{-}=9.14, \mathrm{~S} . \mathrm{d}=3.62$ \\
\hline Areas Used in & $10-17$ & 11 & 17.75 & 67.91 & Correlation $=0.138$ \\
\hline \multirow[t]{2}{*}{ fishing / $\mathrm{sq}^{2}$} & $18-25$ & 31 & 50 & 69.35 & Non-Sign \\
\hline & $26-33$ & 20 & 32.25 & 70.45 & $\mathrm{X}^{-}=22.32, \mathrm{~S} . \mathrm{d}=4.59$ \\
\hline Participation in & Not-Participating & 38 & 61.29 & 68.76 & Correlation $=-0.044$ \\
\hline training courses & Participants & 24 & 38.71 & 70.54 & $\begin{array}{l}\text { Non-Sign } \\
\mathrm{X}^{-}=0.38, \mathrm{~S} . \mathrm{d}=0.47\end{array}$ \\
\hline Exposure to & Low (10-16) Degree & 27 & 43.54 & 71.14 & Correlation $=0.024$ \\
\hline informational & Medium (17-23) & 21 & 33.87 & 68.40 & Non-Sign \\
\hline
\end{tabular}




\begin{tabular}{|c|l|c|c|c|l|}
\hline sources & High (24-30) & 14 & 22.59 & 68.31 & $\mathrm{X}^{\circ}=18.09$, S.d=4.43 \\
& & & & & \\
\hline \hline & \multicolumn{1}{|c|}{ Sources } & $\mathrm{N}$ & Rank & Means & N=62 Responders \\
\hline \hline Types of & Friends and Relatives & 44 & 1 & 2.08 & Max = 44 \\
\hline \hline Information & Agricultural Book & 42 & 2 & 2.01 & Min =11 \\
\hline \hline Sources & Hunters Association & 37 & 3 & 1.97 & \\
\hline \hline & Websites internet & 35 & 4 & 1.93 & \\
\hline \hline & Agricultural Directorate & 26 & 5 & 1.79 & \\
\hline \hline & Agricultural Publication & 24 & 6 & 1.73 & \\
\hline \hline & Experts and Researchers & 15 & 7 & 1.70 & \\
\hline \hline & Extension Department & 13 & 8 & 1.67 & \\
\hline & TV and/or Radio & 11 & 9 & 1.56 & \\
\hline
\end{tabular}

As a result Table 4 shows the distribution of socio-economic variables among the study population. The Age respondents category in this study were aged between $20-49$ years old as well as there was a correlation between Age and Awareness level of the respondents in general at a level (0.05). This result is due to the degree of Awareness level of the respondents, in general, were Increases its value by increasing age years. The results also showed that $79 \%$ of respondents have experience in hunting between 2-13 years as well as there was a correlation between the Awareness level of the respondents and the duration of experience in fishing at a level (0.01). This result is due to the awareness' level of the respondents to the practices of environmental mistakes in general increases dramatically with fishing practices with fishing and non-fishing practice over time which increases their cognitive and skill abilities to face environmental risks and reduce their effects, as well as the data, show that $82.25 \%$ of respondents used Areas in hunting between 18-33 sq2. and there was no correlation between the Awareness level of the respondents in general and the Areas used in hunting. This result is due to that whenever respondents use large areas of fishing in the lake, they can't control the negative consequences of fishing and environmental mistakes that affect their awareness of the consequences of making mistakes as pollution of the water, soil, and air environment of Dukan. Lake in Sulaimaniyah Governorate.

And the data show that $61.29 \%$ of respondents were participants in training courses and there was no correlation between the Awareness level of the respondents in general and the number of participants in the training course. This result is due to that the differences between participants 
and non-participants in the training courses are due to the lack of knowledge of environmental information and its effects on fishing during their participation in the training course.

Additionally, the data show that $77.41 \%$ of respondents, the degree of exposure to sources of information ranges from 10-23 degrees, and there was no correlation between the Awareness level of the respondents in general and exposure to sources of information. It may be because respondents will not have access to printed and unprinted information sources related to environmental awareness and the machine is being treated with factors that pollute the environment in general. Or this is because the majority of respondents have a limited level of education and rely solely on one source: relatives and friends. As well as regard to the ranking of information sources, the results show that Friends and Relatives came in the first rank with an average of 2.08, while Radio and Television source came in the last rank and an average 1.73 according to relative importance.

\section{Conclusions}

1. The awareness level of most Hunters related to making environmental mistakes tends to be low and it was $82.25 \%$.

2. The results indicate that there are differences of relative importance in the means level of Hunters' awareness that causes water pollution, soil and air pollution levels, respectively, It is concluded that the degrees of Hunters' awareness that cause water pollution of the environment has a positive impact on the areas of the soil environment and air pollution, as well as this, leads to acquiring new and desirable behaviors or modifying the wrong existing behaviors in the areas of environmental pollution.

3. The results indicate that there is a significant correlation between the respondents 'awareness level regarding committing environmental errors in general and each of the variables: Age, Duration of experience in fishing. It is concluded that an increase in the age of the respondent is closely related to the level of environmental awareness and the reduction of the errors that result in pollution of the water environment as well as the respondents 'years of experience working in fishing increased, the respondents' level of awareness increased as a result of fishing practices directly and their knowledge of the nature and topography of the study area.

4. This study can help agricultural extension directorates and program planners to develop a plan to develop the abilities of fishermen and change their cognitive and skill behavior by opening training courses and making scientific recommendations to fishermen to preserve natural resources and the environment in the Kurdistan region - Iraq.

5. The study recommended strengthening and supporting the agricultural sector especially fisheries to reduce its negative effects. And avoid it by providing fishing supplies and changing the behavior of hunters by the Ministry of Agriculture and Water Resources in the Kurdistan Region.

\section{Conflict of interest}

The authors declare that they have no conflict of interest. 


\section{Acknowledgments}

We thank everyone who cooperated with us in completing the research.

\section{References}

Abdul Ghaffar, T. 1975. Agricultural Extension between Philosophy and Practice, New Publications House, Alexandria, Egypt. (In Arabic)

Abdul Salam, Z., Al-Abidin, A., Tantawi, H. 1992. Environmental pollution price for the city, Academic Library, Cairo. (In Arabic)

Alloush, Q. M. A. 2016. Lectures on Environmental Pollution, Department of Environmental Management, Collage of Management and Economics, Babylon University, Iraq. (In Arabic) See more at : http://www.uobabylon.edu.iq/uobColeges/lecture_view.aspx?

Al-Abbassi, A. F. 2018. Methods of Scientific Research and Statistical Analysis in Behavioral Sciences, $1^{\text {ST }}$ Edition, Alnoon for Printing and Press, Mosul, Iraq. (In Arabic)

Al-Adly, A. 1973. Basics of Agricultural Extension Science, New Publications House, Alexandria, Egypt. (In Arabic)

Al-Najjar, M., S. 1992. Pollution of the Environment in Egypt - Risks and Solutions, Egyptian General Book Authority, Egypt. (In Arabic)

Arafat, M., AM \& Tantawy, H., H 1992. Pollution of the Environment at the Price of a Civil, Academic Library, Cairo, Egypt. (In Arabic)

Arnaout, M., A. 1993, Man and Environmental Pollution, Egyptian-Lebanese House, Cairo. (In Arabic)

AS. P, D. WR (The Arab Society for the Protection and Development of Water Resources). 2010. Scientific symposium on the environmental impacts of Lake Mariout, Alexandria, Egypt. (In Arabic)

Al-Saffty, W., S. 2008. Effectiveness of the application of a proposed system for managing the quality of the home environment, Department of Family and Children Institutions, Faculty of Home Economics, Helwan University, Egypt. (In Arabic)

Holum, j. 1997. Topic and Terms in environmental problem, john wileyned Ed. New York.

K4D (Institute of Development Studies). 2018. Environmental risks in Iraq, Helpdesk reports By Commissioned by the UK Department for International Development and other Government departments. See more at:

https://assets.publishing.service.gov.uk/media/Environmental_risks_in_Iraq.pdf

Mohammed, S. Saeed, 2019. Fishing and non-fishing activities in fishing exclusion zones during the time of prohibition. Seasonal Report issued by the Department of Fisheries, Directorate General of Livestock and Veterinary, Ministry of Agriculture and Water Resources, Kurdistan Region, Iraq. (In Kurdish)

M.A.W.R (Ministry of Agriculture and Water Resources). 2020. Dam and Water Management, Annual Reports , Unpublished, Directorate of Dams in Kurdistan Region. (In Kurdish)

Nathanson, J. 2000. Basic Environmental Technology, $3^{\text {rd }}$ Ed, printing Hall. New Jersey 
Nature Iraq , 2004. Surveying areas to Identify sites with the highest biodiversity and best water quality. See more at: www.naturiraq.org

N. I. P (Nature Iraq Pub). 2001. Challenges facing Iraq's Environment, NI-0509, Kurdistan Region, Iraq. See more at: http://www.uobabylon.edu.iq/sustainabilty/files/Challenges Environment.pdf

Rahim, Softwires, 2020, IBM SPSS Statistics 22 Free download, See more at: https://rahim-soft.com/ibm-spss-statistics-22-download/

Thair, J. M. 2020. The phenomenon of Water pollution and its quality in the Dokan lake . Annual Report Issued by Department of Health Prevention in Dokan District, Directorate General of Health, Sulaimaniyah Governorate. (In Kurdish)

World, B. 2017. Iraq - Systematic Country Diagnostic (English). Washington, D.C.: World Bank Group P:98. See more at: http://documents.worldbank.org/curated/en/ Iraq-Systematic Country-Diagnostic

Zahran,Y.A.,A. and Qasim.H.S.M. 2005. Fundamentals of Agriculture Extension, Department of Agricultural Extension and Rural Development, Faculty of Agriculture, Mansoura University, Egypt. See more at: https://slideplayer.com/slide/14118207/ 